\title{
DETERMINATION OF CONVECTIVE, RADIATIVE, AND TOTAL HEAT TRANSFER CHARACTERISTICS OVER A RADIANT HEATED CEILING: A COMPUTATIONAL APPROACH
}

\author{
Ozgen Acikgoz ${ }^{*}$
}

\begin{abstract}
In the present study, a computational investigation is carried out within a model room of which dimensions has also been given in international standards for experimental approaches. In accordance with the experimental standards, the analyses are realized at the room dimensions of $(\mathrm{L} \times \mathrm{H} \mathrm{x} \mathrm{W}=4 \times 3 \times 4 \mathrm{~m})$, and at the thermal boundary conditions of $\left(\mathrm{T}_{\mathrm{c}}=35-50^{\circ} \mathrm{C}\right),\left(\mathrm{T}_{\mathrm{w}}=15-24^{\circ} \mathrm{C}\right),\left(\mathrm{T}_{\mathrm{f}}=15-24^{\circ} \mathrm{C}\right)$. As a result of iterations conducted using a computational fluid dynamics package program code, each corresponding to a case study, convective, radiative, and total heat fluxes from radiant heated ceiling are obtained, and afterward using relevant reference temperature proposed in the literature, heat transfer coefficients pertaining to convection, radiation, and total heat transfer have been found. In conclusion, average heat flux values of $95.83 \mathrm{Wm}^{-2}$ and $17.49 \mathrm{Wm}^{-2}$ are gained through the examined radiant heated ceiling, by means of radiation and convection, respectively. This denotes that roughly $85 \%$ of total heat transfer from the ceiling arises through radiation that is very compatible with the relevant literature. Finally, spanning the entire different case studies, average convective, radiative, and total heat transfer coefficients of $1.1 \mathrm{Wm}^{-2} \mathrm{~K}^{-1}, 5.4 \mathrm{Wm}^{-2} \mathrm{~K}^{-1}$, $7.6 \mathrm{Wm}^{-2} \mathrm{~K}^{-1}$ are acquired.
\end{abstract}

\section{Keywords: Ceiling Heating, CFD, Radiation, Convection INTRODUCTION}

On radiant heating and cooling applications, numerous studies exist in the relevant literature. While some of them are experimentally carried out investigations, significant portion of them are numerical studies. This arises from the fact that building up an experimental chamber providing stable thermal conditions which results in trustable outcomes, is not only difficult but also expensive. This stems from the difficulties in preparing hydronic circuits connected to a chamber equipped with well-protection from surrounding environment. Therefore, remarkable amount of experimental radiant heating works were conducted by means of electrically heated panels mounted on surfaces of enclosures, whereby, implementation of experiments was quite facilitated. Moreover, numerical studies via CFD (Computational Fluid Dynamics) programs were done to simulate a room of which surfaces had been heated/cooled by means of either constant heat flux or constant surface temperature boundary conditions.

With regard to reaching thermal comfort zone, the forth - coming point of radiant heating and cooling systems is that relatively lower radiant surface temperatures and higher radiant surface temperatures in heating and cooling modes bring about significant decrease in convective heat transfer and thus lower amount of air movements. To summarize the recently published papers, a short but dense literature review is given in the following paragraphs.

Wu et al. [1] progressed a new model to calculate surface temperatures and heat transfer for radiant systems, by using conduction shape factor. The data gained showed that the differences between found surface temperatures and heat transfer through the suggested model and the measured data were determined as $0.8^{\circ} \mathrm{C}$ and $8.1 \mathrm{~W} / \mathrm{m}^{2}$, while the average water temperature was within the range of $40^{\circ} \mathrm{C}$ and $60^{\circ} \mathrm{C}$.

To ascertain the relation between the solar radiation utilization ratio and the supply heating temperatures, along with evaluating the efficiency of the radiant capillary module and the thermal comfort of the system for effective applications, Zhao et al. [2] have done a set of experiments in a residential building in a province of China. As a conclusion, they have deduced that by reducing the supply water temperatures, energy consumption of the system may be noticeably get better, in case the supply water temperature is below $35^{\circ} \mathrm{C}$.

This paper was recommended for publication in revised form by Regional Editor Bekir Yilbas

${ }^{1}$ Department of Mechanical Engineering, Yildiz Technical University, Istanbul, Turkey

${ }^{*} E$-mail address: oacikgoz@yildiz.edu.tr

0000-0002-0095-829X

Manuscript Received 01 Feb 2018, Accepted 13 August 2019 
Evren et al. [3] carried out a variety of measurements in an experimental chamber whose surface temperatures and the dry-bulb air temperature were kept under control. The authors utilized two type of electric fan heaters, which have the same heating potentials, whereas different fan outputs, to employ it combined with a hydronic floor heating system. In the experiments, the floor system, and the fan heaters were performed at a number of heating outputs and hence radiation and convection ratios were varied while energy consumption data were being saved. As a result, it was concluded that radiative-convective ratio was lying within the range of 0.65 to 0.75 .

Zhao et al. [4] examined the performance of a radiant floor heating and cooling application employed in an international airport. They indicated that the radiant floor application provided a heating output of 30 to $70 \mathrm{~W} / \mathrm{m}^{2}$, while the hot water temperature fluctuates between 35 and $40^{\circ} \mathrm{C}$ that may be evaluated as a trustable choice to cover heating requirements.

Zhang et al. [5] employed a model of a radiant ceiling cooling system used in association with an underfloor ventilation system. For this aim, they asserted a dynamic simplified resistance and capacity network of the mentioned combination. Via least square method, the authors determined thermal resistances, capacities and convective heat transfer coefficients of the model. To verify the accuracy of the developed model, seven case studies were made, while identification of the parameters were done via experimental data. As a result, authors have concluded that operative differences are less than $0.5 \mathrm{~K}$, as inaccuracy of ceiling heat flux are within a range of $7.7 \%$, between case studies and measured results.

By operating the program EnergyPlus, Bojic et al. [6] noted that the newly developed floor and ceiling radiant heating system had the most efficient performance, whereas, the conventional ceiling heating had the worst performance. On the other hand, it was estimated that in the upcoming days, with the decrease of primary energy consumption coefficient $(\mathrm{R})$ the panel heating using ground source heat pump as heating source might have less total energy consumption than a system consuming natural gas.

Feng et al. [7] had a purpose of examining the effects of solar radiation on floor cooling capacity, as well as, forming a new and easy path to estimate the output of radiant floor cooling system, when direct solar radiation exists. They operated the program EnergyPlus to assess the influences of solar at a set of design conditions. As a conclusion, the results indicated that the actual cooling capacity were 1.44 times higher than the values calculated with ISO 11855 method, while the number is 1.2 times higher than that of ASHRAE method.

Bojic et al. [8] have individually investigated radiant heating systems used by means of all surfaces of rooms. It was demonstrated that the floor-ceiling had had the most favorable efficiency with regard to energy consumption, environmental fronts, and economy. Moreover, the least preferable system among different surface heating applications was found as the classical ceiling heating.

Shin et al. [9] generated design charts to evaluate heat flux, difference between maximum and minimum floor surface temperatures, and maximum floor surface temperatures in the design stage, through analyzing the correlation between heat flux and design parameters, alongside carrying out numerical case studies to determine temperature distributions on floor surfaces. By means of experimental investigations, the authors have validated whether the charts are providing true results.

Awbi [10] has reported the outcomes of a numerical investigation on convective heat transfer coefficients over a heated floor, wall, and ceiling. For this purpose, he employed two turbulence models: a standard k- $\varepsilon$ model using wall functions and a low Reynolds k- $\varepsilon$ model. The numerical outcomes were compared with those found by means of two different experimental rooms.

In addition to the numerical efforts in the field, Giovanelli and Bashir [11] have published a work on the design and analysis of a solar receiver. The main point of the work associated with the present investigation is that the authors to study the charge and discharge mechanism of the storage system that is combined with the solar receiver, using a CFD approach. The method implemented by the authors has composed an insightful path with regard to the way that should be followed through a CFD approach and a beneficial frame over the system they analyzed from a thermodynamics and heat transfer point of view.

In addition to the recently published articles summed up in this section, the articles and some international standards mainly focused on estimating heat transfer coefficients should be mentioned [12-22]. Either they are experimental or numerical, the significant part of these papers are related to convection. This is because, the radiative 
heat transfer in enclosures is calculated mainly by a method named net - radiosity method, and almost constant radiative heat transfer characteristics have been obtained in the extant literature. Therefore, the point still at some extent, has necessitated further investigation is the convective phenomenon which also determines the total heat transfer characteristics over a radiant heated/cooled surface.

To respond to this purpose, in the present study, the heat transfer characteristics pertaining to a radiant ceiling heating system are investigated in a numerically modeled room at the dimensions of $\mathrm{LxHxW}=4 \mathrm{x} 3 \mathrm{x} 4 \mathrm{~m}$, and at the thermal boundary conditions of $\left(\mathrm{T}_{\mathrm{c}}=35-50^{\circ} \mathrm{C}\right),\left(\mathrm{T}_{\mathrm{w}}=15-24^{\circ} \mathrm{C}\right),\left(\mathrm{T}_{\mathrm{f}}=15-24^{\circ} \mathrm{C}\right)$. The emissivity value of all surfaces was assumed 0.9 which is a reasonable, but also commonly measured value in experimental chambers. In the current investigation, using the programs DesignModeler and FLUENT in the package program ANSYS 14, the chamber is drawn and the governing equations related to the air flow within the chamber along with the radiation heat transfer problem between surfaces are solved in accordance with the prevalently acknowledged CFD solution approximation. Moreover, to generalize the behavior of convection and radiation over a heated ceiling in a room, a correlation which is a function of convective and radiative heat transfer coefficients found using the CFD approach, as well as of temperature difference between ceiling surface temperature and air temperature in the middle of the chamber, is derived and contributed to the literature for future researchers to compare their results.

\section{THEORETICAL CALCULATIONS}

Total heat transfer rate by the panels $\left(Q_{t}\right)$; is composed of the radiative heat transfer emitted to the surrounding surfaces $\left(Q_{r}\right)$, and convective heat transfer $\left(Q_{c}\right)$ arising between radiant surface and the air. This energy equivalence is given in Equation 1.

$$
Q_{t}=Q_{r}+Q_{c}
$$

The total heat flux rate balance can also be gained with Equation 2.

$$
h_{t}\left(T_{s}-T_{o p}\right)=h_{r}\left(T_{s}-A U S T\right)+h_{c}\left(T_{s}-T_{a}\right)
$$

The radiative heat transfer coefficient is found with the help of AUST of which calculation way is presented in Equations 3-5.

$$
\begin{gathered}
A U S T=\sqrt[4]{\sum_{j=1}^{n}\left(F_{s-j} T_{j}^{4}\right)} \\
F_{\varepsilon_{s-j}}=\frac{1}{\left[\left(1-\varepsilon_{s}\right) / \varepsilon_{s}\right]+\left(1 / F_{s-j}\right)+\left(A_{s} / A_{j}\right)\left[\left(1-\varepsilon_{j}\right) / \varepsilon_{j}\right]} \\
F_{s-j}=\frac{1}{A_{i}} \int_{A_{i}} \int_{A_{j}} \frac{\cos \theta_{i} \cos \theta_{j}}{\pi R^{2}} \mathrm{dA}_{i} d_{A_{j}}
\end{gathered}
$$

The radiant heat-flux $\left(\dot{\mathrm{q}}_{\mathrm{r}}\right)$ from the heated surfaces to the other surfaces is obtained through Equation 6 and the coefficient symbolizing the pertaining heat transfer is attained by Equation 7.

$$
\dot{\mathrm{q}}_{\mathrm{rad}=} \sigma \sum_{\mathrm{j}=1}^{\mathrm{n}} \mathrm{F}_{\varepsilon_{\mathrm{s}-\mathrm{j}}}\left(\mathrm{T}_{\mathrm{s}}^{4}-\mathrm{T}_{\mathrm{j}}^{4}\right)
$$




$$
\mathrm{h}_{\mathrm{r}}=\frac{\mathrm{q}_{\mathrm{r}}}{\mathrm{T}_{\mathrm{s}}-\mathrm{AUST}}=\frac{\sigma \sum_{\mathrm{j}=1}^{\mathrm{n}} \mathrm{F}_{\varepsilon_{\mathrm{s}-\mathrm{j}}}\left(\mathrm{T}_{\mathrm{s}}^{4}-\mathrm{T}_{\mathrm{j}}^{4}\right)}{\mathrm{T}_{\mathrm{s}}-A U S T}
$$

For the entire surface emissivity values input in the program FLUENT, the value 0.9 has been employed. This value is prevalently used in the calculation method of radiative heat transfer between room surfaces, and also in experimentally found value of this parameter is roughly 0.9 .

Equation 8 provides the total heat transfer coefficient $\left(\mathrm{h}_{\mathrm{t}}\right)$, in which, the total heat-flux density $\left(\dot{\mathrm{q}}_{\mathrm{t}}\right)$ is the sum of the radiative $\left(\dot{\mathrm{q}}_{\mathrm{r}}\right)$ and the convective $\left(\dot{\mathrm{q}}_{\mathrm{c}}\right)$ heat transfer heat-flux.

$$
\mathrm{h}_{\mathrm{t}}=\frac{\dot{\mathrm{q}}_{\mathrm{t}}}{\mathrm{T}_{c}-\mathrm{T}_{\mathrm{s}}}
$$

The convective heat transfer coefficient between the heated surfaces and room - depends on the heat-flux densities, heated surface and air temperatures - was acquired with Equations 9-10.

$$
\begin{aligned}
& \mathrm{q}_{\mathrm{c}}=\dot{\mathrm{q}}_{\mathrm{t}}-\dot{\mathrm{q}}_{\mathrm{r}} \\
& \mathrm{h}_{\mathrm{c}}=\frac{\dot{\mathrm{q}}_{\mathrm{c}}}{\mathrm{T}_{\mathrm{c}}-\mathrm{T}_{\mathrm{a}}}
\end{aligned}
$$

\section{CFD APPROACH}

With the advancements in computer processors, the utilization of CFD programs for the determination of heat transfer characteristics in living areas has become reasonable. However, despite significant progression, reaching ultimate solution of iterations, in such large geometries, such as the office in the present study, has still taken notable amount of time. To mitigate this, generating cells close to the edges more frequent and preparing less frequent toward the center of the office have been applied, and thus enabling solutions in tolerable periods along with trustable accuracy has become possible. It should be noted that the present investigation provides results obtained within a wide range of thermal boundary conditions mentioned in Introduction Section.

A three dimensional model is generated to reach the findings of the present study. The governing equations are given for the steady-state air consisting of related models such as buoyancy influences, turbulent dispersion, and radiant heat transfer model. The equation of continuity in Equation 11, momentum in Equation 12, and energy equation in Equation 13 are given below for steady-state analyses:

$$
\begin{gathered}
\frac{\partial}{\partial x_{i}}\left(\rho u_{i}\right)=0 \\
\frac{\partial}{\partial x_{i}}\left(\rho u_{i} u_{j}\right)=-\frac{\partial p}{\partial x_{i}}+\frac{\partial}{\partial x_{j}}\left[\mu\left(\frac{\partial u_{i}}{\partial x_{j}}+\frac{\partial u_{j}}{\partial x_{i}}-\frac{2}{3} \delta_{i j} \frac{\partial u_{l}}{\partial x_{l}}\right)\right]+\frac{\partial}{\partial x_{j}}\left(-\rho \overline{u_{i}^{\prime} u_{j}^{\prime}}\right) \\
\frac{\partial}{\partial x_{i}}\left(\rho u_{i} h-\lambda \frac{\partial T}{\partial x_{i}}\right)=u_{i} \frac{\partial p}{\partial x_{i}}+\tau_{i j} \frac{\partial u_{i}}{\partial x_{i}}
\end{gathered}
$$

where, $\mathrm{S}_{\mathrm{ij}}$ and $\tau_{i j}$ are mean rate of strain tensor and viscous stress tensor, respectively as shown in Equations 14 and 15. 


$$
\begin{gathered}
\tau_{i j}=2 \mu S_{i j}-\frac{2}{3} \mu \frac{\partial u_{l}}{\partial x_{l}} \delta_{i j} \\
S_{i j}=\frac{1}{2}\left(\frac{\partial u_{i}}{\partial x_{j}}+\frac{\partial u_{j}}{\partial x_{i}}\right)
\end{gathered}
$$

Solving governing equations (continuity, momentum, and energy) requires a package program to be employed. For this purpose, initially, the simulated office was drawn and meshed by means of the program DesignModeler within ANYSY 14, and then, thermal boundary conditions were input and necessary options such as the turbulence model to be used, was selected in the program FLUENT. Figure 1 illustrates the office meshed as it is depicted in the previous lines.

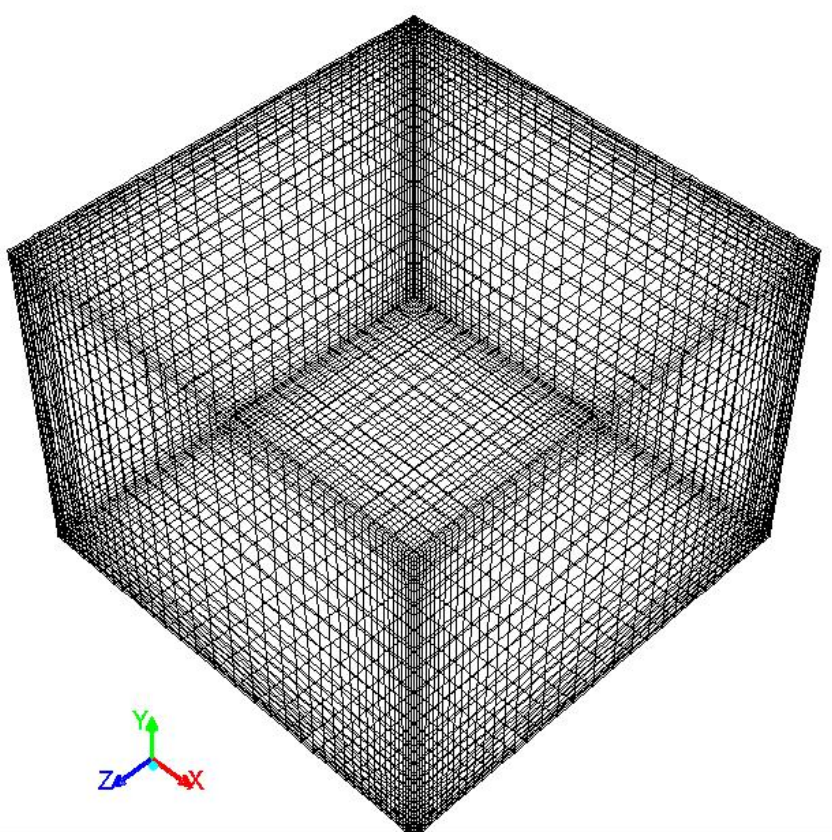

Figure 1. Meshing of modeled office (Lx H x W $=4$ x 3 x 4 m)

The program's solution method is established on the control volume theory, ie. by means of turning relevant equations into algebraic equations for them to be solved [23]. Because, usage of mentioned plausible thermal boundary conditions result in turbulent flow over the ceiling, -due to Rayleigh numbers greater than $10^{9}$-, a turbulence model has been chosen. The type of k- $\varepsilon$ model was determined as the k- $\varepsilon$ RNG model, in accordance with the proposal of Seyam et al. [24]. The under - relaxation factors pertaining to density, momentum, turbulence kinetic energy turbulence dissipation rate, turbulent viscosity and energy have been selected 1.0, 2.0, 0.8, 0.8, 1 and 0.9 , respectively. It should also be noted that it took about 3 hours, the program to reach proposed residual values of $10^{-3}$ and $10^{-6}$, for momentum/continuity and energy equations, respectively. Additionally, thermos - physical properties of air were entered for the air temperature value at the center of the enclosure, obtained from the air's thermos - physical tables of Incropera and DeWitt [25]. Also, the Boussinesq approach has been selected, because in natural convection it is strongly recommended by the program manual. Such as in hydronic radiant heating applications, a constant surface temperature has been preferred in the present work, to gain realistic outcomes. It should also be expressed that density - based coupled solver was determined as the solver. The gravitational force was also entered in the y direction as $9.81 \mathrm{~m} / \mathrm{s}^{2}$. 
In addition to the points and selections made which should be considered while conducting a CFD simulation, one issue which should also be taken into account is independency of results from cell numbers within the simulated chamber. To ascertain whether the influence of meshing structure is sufficiently minimized or not, the Nusselt numbers are acquired through the program's area weighted average specialty. It should also be noted that the Nusselt number over the heated surface points out to convective heat transfer along this surface and can be assessed as a reference in this context. Altering interval counts at $\mathrm{x}, \mathrm{y}$, and $\mathrm{z}$ axes generates the diverse total cell numbers in the air, and this can be observed in Table 1.

It is clear that at the same thermal boundary conditions, in case the total cell number rose from 50625 to 90750, the Nusselt number deviated less than $1 \%$. Moreover, since the results corresponding the abovementioned meshing numbers are so close, the interval combination next to the last one, corresponding to 50625 cells was determined as the appropriate option, and thus it was deduced that the effect of cell numbers on the results have been averted. From this point on, the case studies were carried out with selected interval count numbers.

To dispel the number of cells on results, at different cell number options, the iterations were done until the abovementioned residual values were reached and concluded that at the total cell number of 50625, the independency of results from total cell numbers had been realized. Hence, whole case studies have been implemented at this total cell numbers.

Table 1. The variation of Nusselt number as the number of cells within the cavity alters

\begin{tabular}{|l|l|l|}
\hline $\begin{array}{l}\text { Combinations of interval } \\
\text { counts in } \mathbf{x}-\mathbf{y} \text {-and } \mathbf{z} \text { axes }\end{array}$ & $\begin{array}{l}\text { Number of } \\
\text { cells }\end{array}$ & Nusselt number \\
\hline $20 \times 20 \times 20$ & 8000 & 140.01 \\
\hline $35 \times 20 \times 35$ & 24500 & 141.87 \\
\hline $45 \times 25 \times 45$ & 50625 & 142.56 \\
\hline $55 \times 30 \times 55$ & 90750 & 142.94 \\
\hline
\end{tabular}

\section{RESULTS AND DISCUSSION}

In case the relevant literature is investigated, one can notice that the most recent papers are related to radiant wall and floor heating and cooling. In addition to this, when the literature is rigorously scrutinized, a significant number of radiant ceiling cooling studies can be met. Nonetheless, it can clearly be observed that radiant ceiling heating systems comprise the least investigated portion in the field. The studies of Causone et al. [12], Koca et al. [13], and Rahimi and Sabernaeemi [26] are the most recent and detailed works in the literature. Nevertheless, by very nature of experimental studies, these works have also been carried out within confined thermal boundary conditions, and implemented in chambers of which dimensions are constant and cannot be altered. Therefore, carrying out case studies in computational fluid dynamics programs such as one used in the present work ANSYS 14, provides researchers and engineers to do these investigations in broader thermal boundary conditions and different room dimensions.

In the light of abovementioned considerations, the present study presents the results of a numerical work which were conducted within a wide range of thermal boundary conditions, and in a simulated room meshed as illustrated in Figure 1. As can be observed from the figure, meshes near edges are maintained highly frequent, while preferring them less frequent toward the center of the chamber. This choice can be accounted for by the fact that in the thermal boundary layers of heated and cooled surfaces, rapid temperature changes occur, and thus effect of these variations ought to be taken into account by frequent cell densities in these regions. Nonetheless, due to the fact that temperature variations out of boundary layer regions that are toward the center are rather negligible, mesh density can be selected much less frequent in this region. By this means, computation duration has also been diminished, otherwise, in large geometries such as that of the present investigation, acquiring a realistic result in reasonable periods would have been unfeasible. 


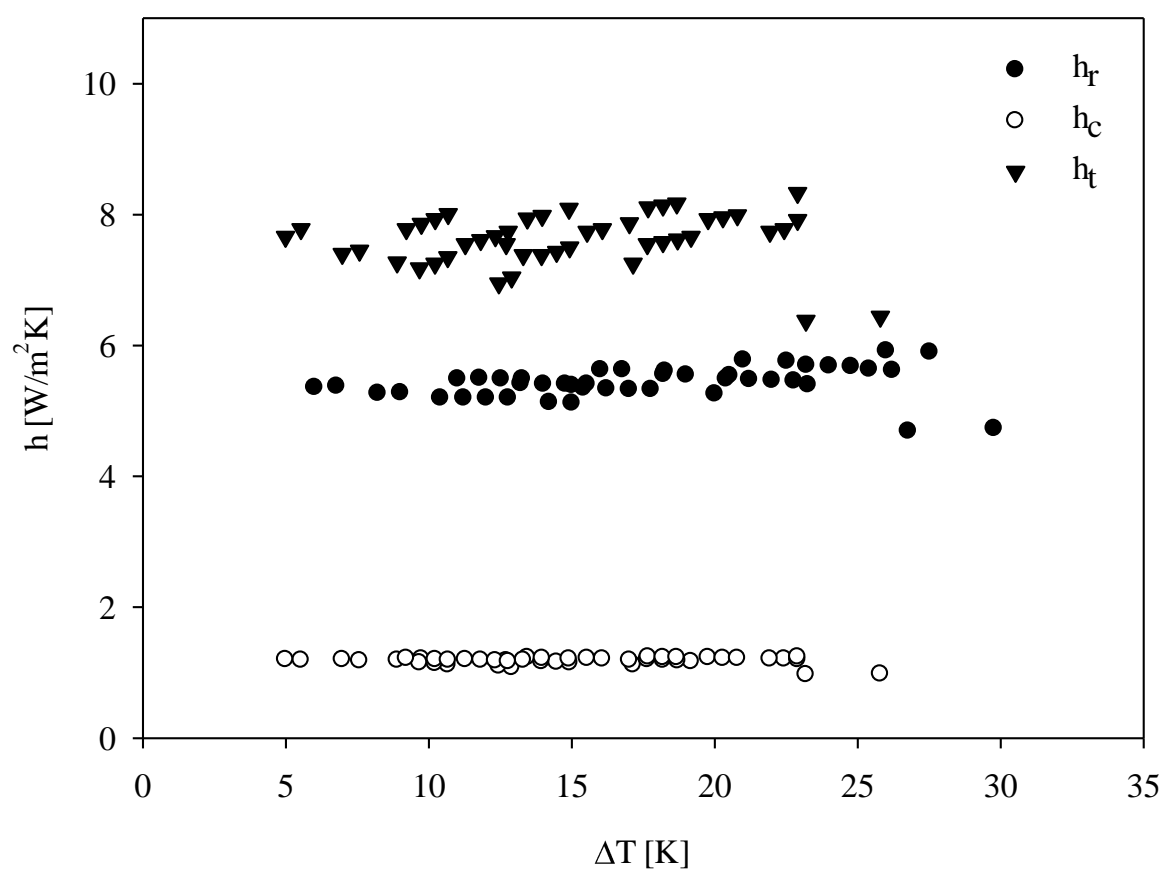

Figure 2. Radiative, convective, and total heat transfers' variation with corresponding temperature difference values

In Figure 2 the variation of radiative, convective, and total heat transfer coefficients with corresponding temperature differences $(\Delta \mathrm{T})$ are indicated. It can be observed from the figure that especially convective and radiative heat transfer coefficients mostly draw an unchanging trend with corresponding temperature values, $\left(\mathrm{T}_{\mathrm{c}^{-}} \mathrm{T}_{\mathrm{a}}\right)$, and $\left(\mathrm{T}_{\mathrm{c}^{-}}\right.$ AUST), respectively. Consequently, it may be deduced that as a result of the present one is able to obtain an average radiative heat transfer coefficient value of $5.4 \mathrm{~W} / \mathrm{m}^{2} \mathrm{~K}$, and an average convective heat transfer coefficient value of 1.1 $\mathrm{W} / \mathrm{m}^{2} \mathrm{~K}$. Though total heat transfer coefficient values appears to be more scattered than that of radiative and convective heat transfer coefficients, the data cluster in the vicinity of $7.5 \mathrm{~W} / \mathrm{m}^{2} \mathrm{~K}$, while an average value of $7.6 \mathrm{~W} / \mathrm{m}^{2} \mathrm{~K}$ is obtained, as a recommendation of the present investigation. Relatively scattered appearance of total heat transfer coefficients in the figure may be attributed to reference temperature selection pertaining to total heat transfer characteristics, which has been a major uncertainty in the relevant research field. In the meantime, it should be noted that in this work the air temperature in the middle of the chamber was used as the reference temperature for total heat transfer characteristics. Figure 3 presents a comparison between the total heat flux of the radiant ceiling system in the present work, and results obtained using the correlation proposed by EN 15377 [17]. As it can be noticed in Figure 2, the relatively scattered trend of the heat flux trend from the present study compared to the results of correlation suggested by EN 15377 [17], can also be accounted for the explanations noted for Figure 2.

In addition to this, between the outcomes of two studies presented in this figure, a slight deviation between the trendlines of studies are discerned. This may be attributed to unavoidable experimental errors in the corresponding study, numerical errors due to the method performed in the current examination, or thermal boundary conditions of surfaces other than the heated ceiling in the present investigation. Nevertheless, the deviation of the results of the correlation of EN 15377 [17] and of the results of this study are very close at lower temperature difference $\left(T_{c}-T_{a}\right)$ values, which are more realistic values, while at higher temperature difference $\left(T_{c}-T_{a}\right)$ values, which are not so realistic in pratice, the deviation grows. Thus, this also elucidates that the explained deviation does not denote that the numerical results of this study to be unrealistic. 


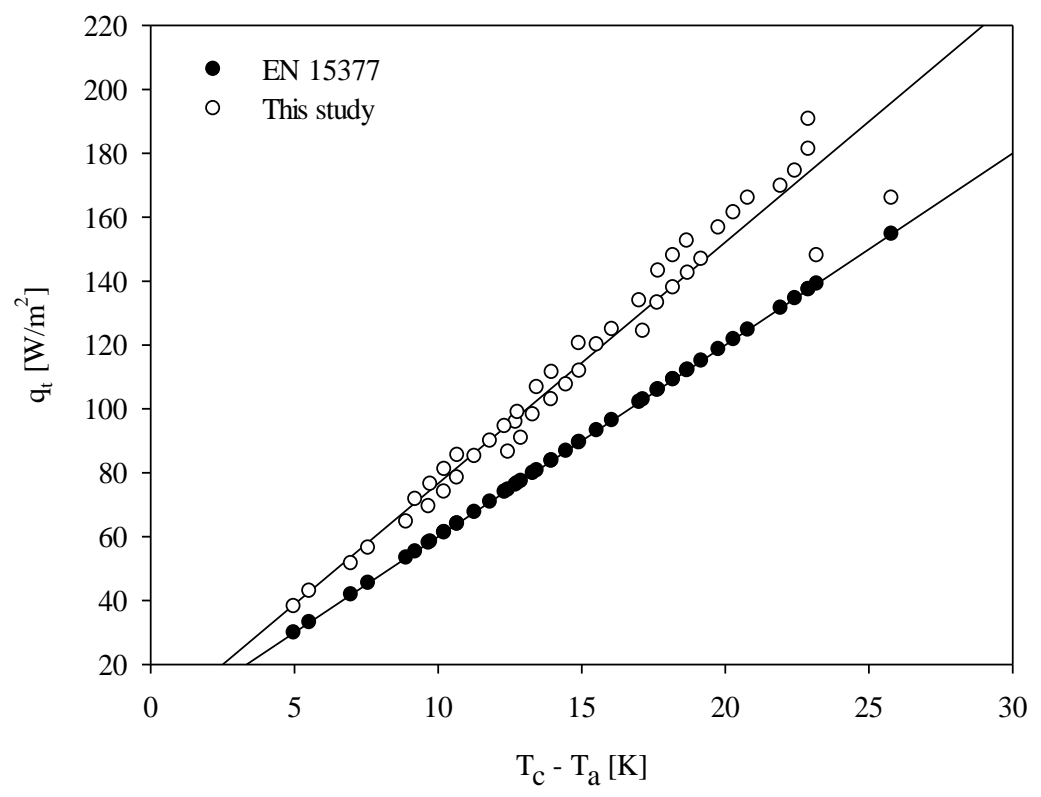

Figure 3. The comparison of total heat flux results of this study and results obtained employing the correlation proposed by EN 15377

Figure 4 illustrates a comparison of the results of study with of Koca et al. [13] and of Causone et al. [12] in both which radiant ceiling heating systems are experimentally analyzed. It should be noted that since in the paper of Causone et al. [12] no AUST value given, the radiative heat transfer characteristic results of this study have not been able to be compared with those of the corresponding work. In terms of convective heat flux, it is evident from the figure that the results of three study are considerably consistent with each other, while results of Causone et al. [12] give the lowest convective heat flux value, the present study results in the highest average, and Koca et al. [13] concludes as the value remaining in the middle. With regard to radiative heat flux, the results of this study, along with that of Koca et al. [13] draw almost the same trend line.

Thus, they are compatible with each other. Total heat flux values slightly deviate from each other possibly due to the differences in convective heat flux results, which is an ingredient composing total heat flux. It is clear from the figure that as in the convective heat flux remarks, despite the fact the differences are not so significant, this study results in highest heat flux outputs, while Causone et al. [12] the lowest, and Koca et al. [13] in the middle of two.

Figure 5 compares the results of this study and of Koca et al. [13] in terms of heat transfer coefficients. It is noticeable that similar to convective heat flux values, convective heat transfer coefficients found via the present study demonstrate a slightly higher tendency than those of Koca et al. [13]. Furthermore, the radiative heat transfer coefficient data from this investigation keep track of the results of Koca et al. [13] almost in the same points, while total heat transfer coefficients of the present work which involves convective heat transfer data illustrate a higher tendency line, because of the higher convective results both indicated with respect to convective heat transfer coefficients in Figure 5 and convective heat flux in Figure 4, of which deviation sources were accounted for in previous paragraph, as interpreting Figure 4. 


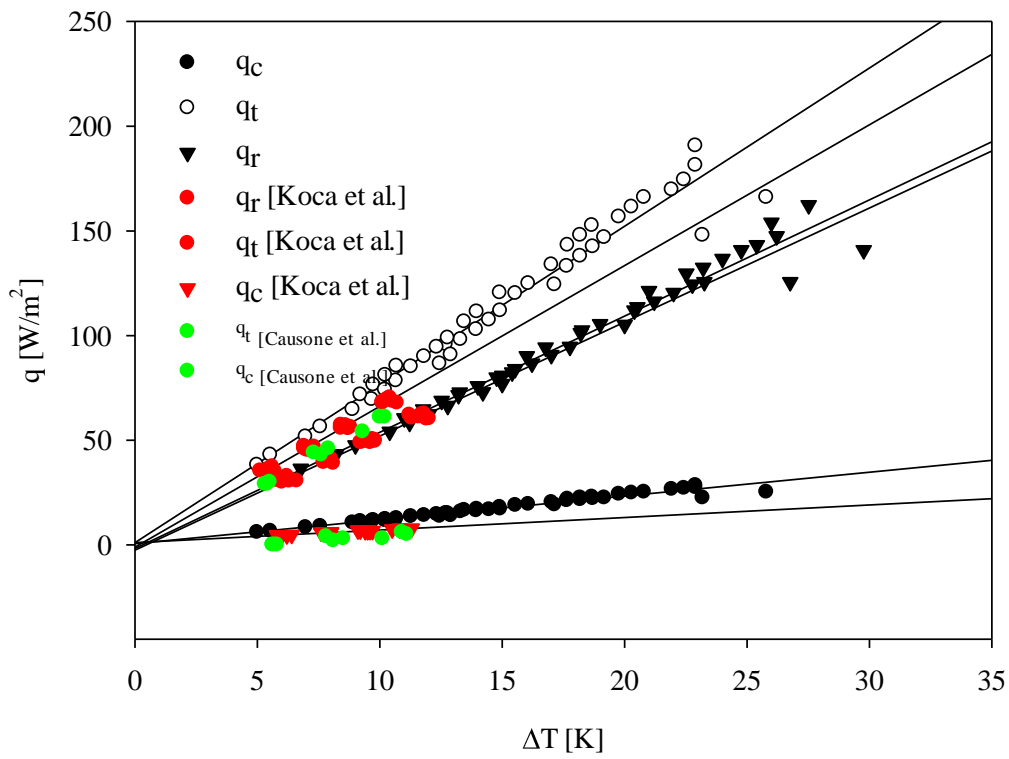

Figure 4. Comparison of convective, radiative, and total heat outputs of the present work, and of experimental results of Koca et al. [11] and Causone et al. [10]

Furthermore, to form a correlation between the radiative and convective findings of the present investigation, an equation valid within the thermal boundary conditions expressed in the last paragraph of Introduction section is produced and can be seen in Equation 16 as follows:

$$
\frac{h_{r}}{h_{c}}=4.11\left(T_{c}-T_{a}\right)^{0.043}
$$

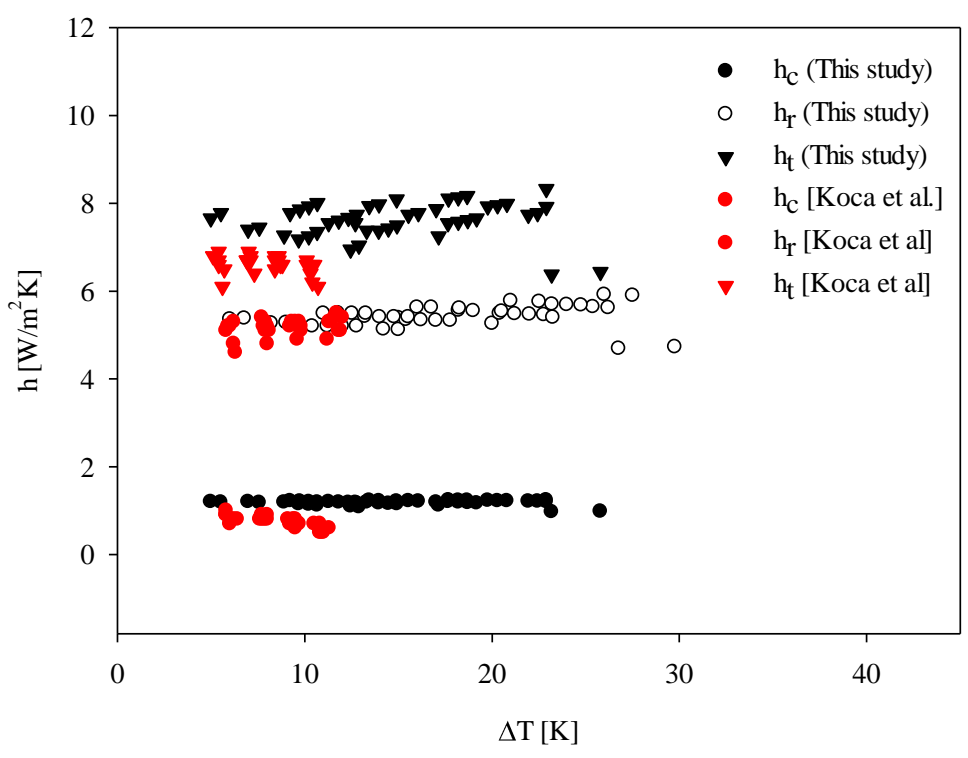

Figure 5. A comparison between heat transfer coefficient findings of the current study, and of experimental study of Koca et al. [11]

To demonstrate the $h_{r} / h_{c}$ ratio results of this study alongside the outputs of the correlation expressed in Equation 16, Figure 6 is generated. As can be seen through the figure, a trend line symbolizing the outweighing behavior of the proportion of radiative and convective heat transfer coefficient, was drawn. It ought to be noted that 
the correlation derived which also symbolizes this line has a maximum deviation ratio of $6 \%$, and an average deviation ratio of $1.2 \%$, which are both satisfactory values, with regard to being a benchmark of obtaining an accurate equation.

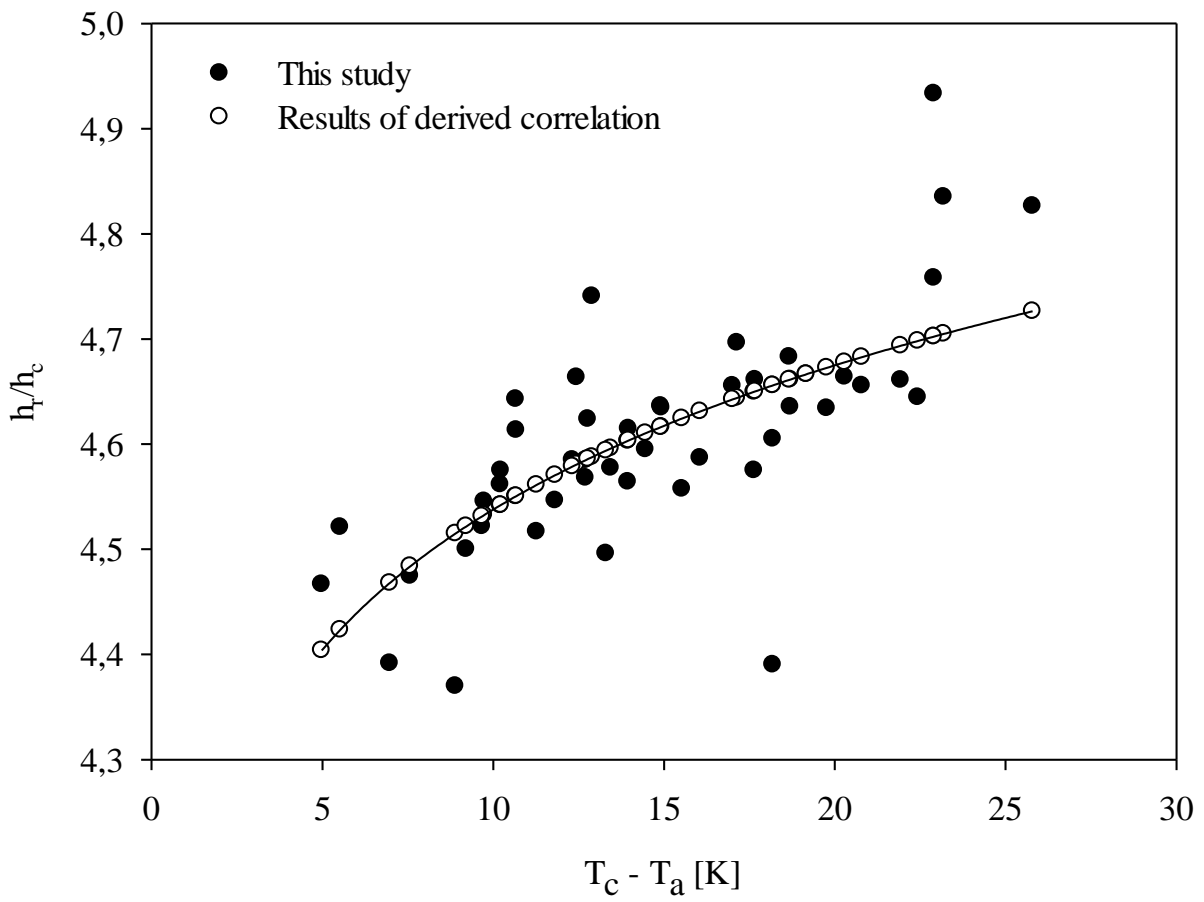

Figure 6. The results of the present study pertaining to the proportion of $h_{r}$ and $h_{c}$, and the results obtained by the Eq. [16] derived for this ratio

Table 1. Comparison of the present work with some other radiant studies in the literature, in terms of heat transfer coefficients

\begin{tabular}{|l|l|c|c|c|}
\hline Researchers & Heating / Cooling type & $\begin{array}{c}\mathbf{h}_{\mathbf{c}} \\
\left(\mathbf{W} / \mathbf{m}^{\mathbf{2}} \mathbf{K}\right)\end{array}$ & $\begin{array}{c}\mathbf{h}_{\mathbf{r}} \\
\left(\mathbf{W} / \mathbf{m}^{\mathbf{2}} \mathbf{K}\right)\end{array}$ & $\begin{array}{c}\mathbf{h}_{\mathbf{t}} \\
\left(\mathbf{W} / \mathbf{m}^{\mathbf{2}} \mathbf{K}\right)\end{array}$ \\
\hline Causone et al. [10] & Radiant ceiling heating & 0,3 & 5,6 & 5,8 \\
\hline Koca et al. [11] & Radiant ceiling heating & 0,7 & 5,2 & 6,6 \\
\hline Cholewa et al. [12] & Radiant floor heating & $2,2-3,4$ & 5,6 & $8,5-10,4$ \\
\hline $\begin{array}{l}\text { Andres - Chicote et al. } \\
\text { [13] }\end{array}$ & Radiant ceiling cooling & 4,2 & 5,6 & 13,2 \\
\hline EN 1264-5 [14] & Radiant heated floor & - & - & 10,8 \\
\hline EN 15377-1 [15] & Radiant heated floor & - & 5,5 & - \\
\hline This study & Radiant heated ceiling & 1,1 & 5,4 & 7,6 \\
\hline
\end{tabular}

In Table 1, the findings of the present paper are compared with studies covering heat transfer coefficients over radiant surfaces. The most similar studies in the literature were compared with those of the present investigation by means of Figures 2-6, however, some other researchers' findings were also assembled in Table 1 for future researchers to have a better idea over various radiant heating and cooling systems in terms of heat transfer characteristics. 

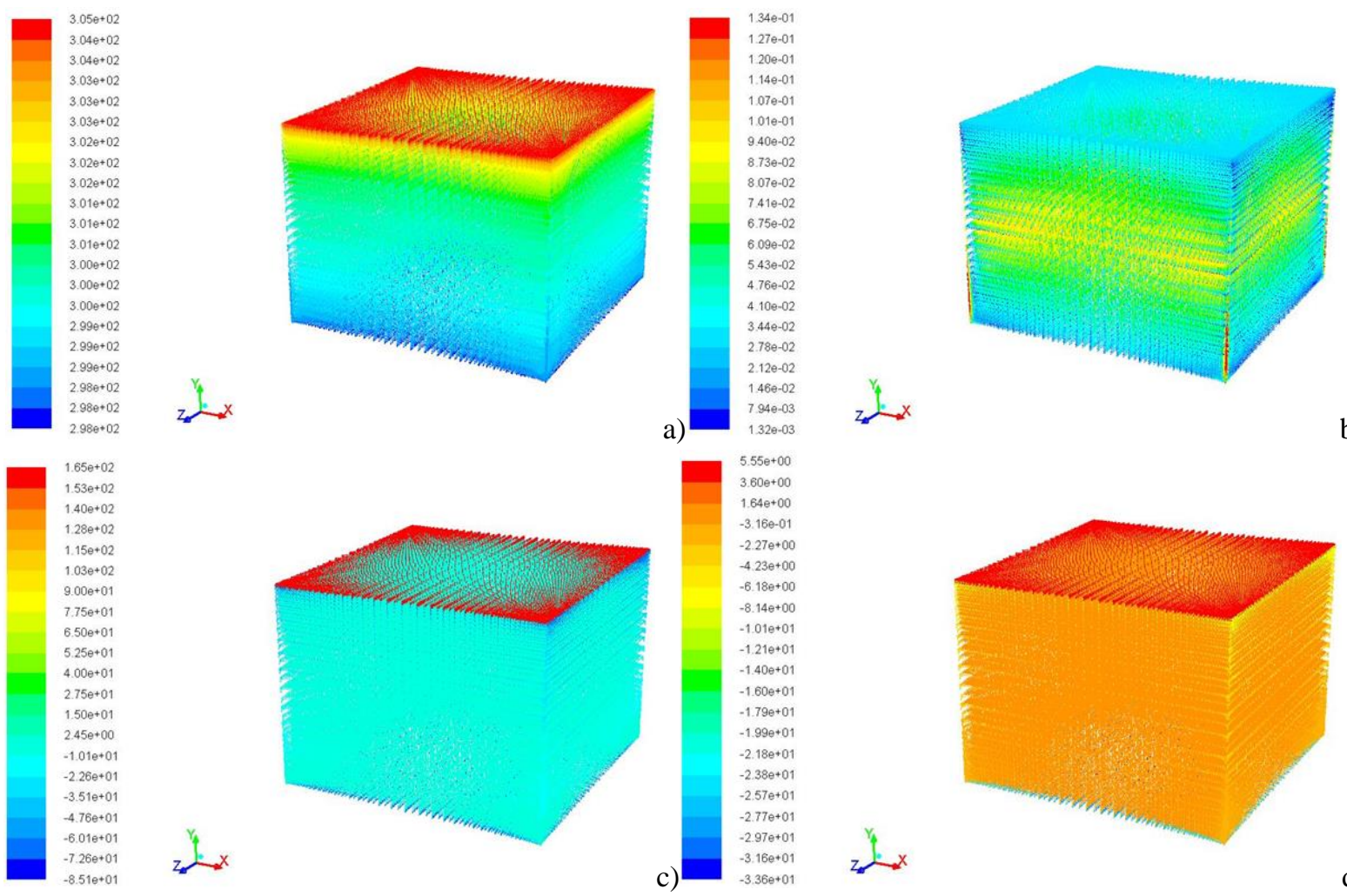

b)
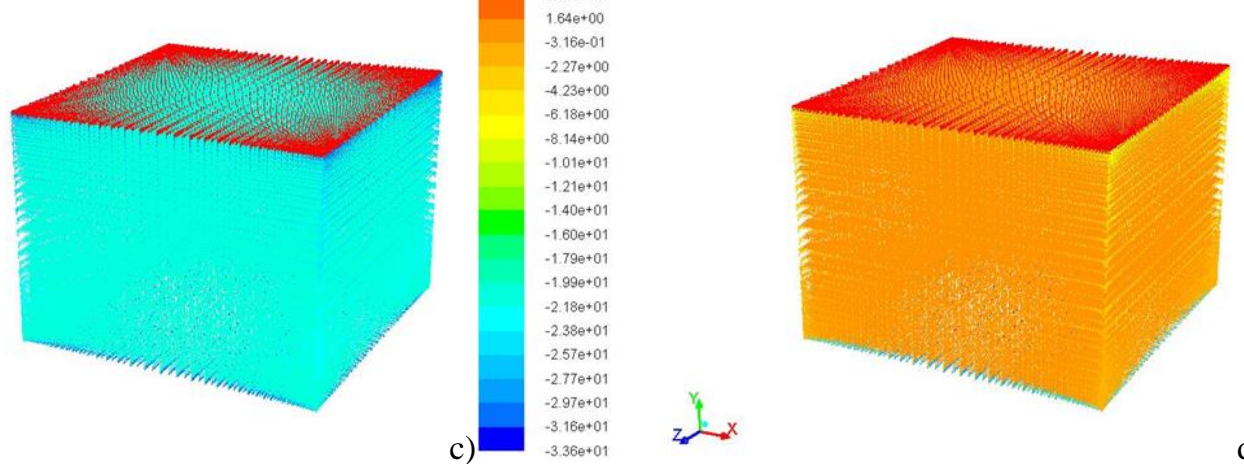

d)

Figure 7. Temperature contours and a number of vectors obtained via CFD application (a) temperature contour, (b) velocity vectors, (c) radiant heat flux vectors, and (d) surface heat transfer coefficient vectors

Figures 7 (a-d) demonstrate a set of contours and vectors along with heat transfer characteristics, in case the thermal boundary conditions of $\left(\mathrm{T}_{\mathrm{s}}=50^{\circ} \mathrm{C}, \mathrm{T}_{\mathrm{w}}=24^{\circ} \mathrm{C}\right.$, and $\left.\mathrm{T}_{\mathrm{f}}=18^{\circ} \mathrm{C}\right)$ are applied to the numerically modeled room whose dimensions are given in Section 1. It is obvious from Figure 7a that radiant heated ceiling results in an gradual thermal stratification next to the heated ceiling, and a less gradual one beside the floor region where air temperature decreases toward the floor, as expectedly. Figure $7 \mathrm{~b}$ reveals velocity vectors in the investigated office, and it is noticeable that over walls highest velocity magnitudes have occurred. This may be because of the difference in temperature and therefore density air particles over walls and ones around the heated ceiling that brings about higher amounts of air movements compared to the core of the air within the model. Figure 7c depicts radiant heat flux vectors in the chamber. It is evident that radiant heat flux vectors over the ceiling adjacent to walls are at the highest values, while ones in the middle of ceiling are less effective. It can also be understood that walls, and floor have negative flux values different than those of the ceiling, as expectedly. Moreover, Figure $7 \mathrm{~d}$ gives total heat transfer coefficients as vectors on surfaces. One can understand through the figure that consistent with the results given via figures and tables, the most intense heat transfer coefficient values have been gained over the ceiling, and it should be noted that the coefficient vectors involve both convection and radiation heat transfer by the examined surfaces.

\section{CONCLUSION}

Suspended nanoparticles play a significant role in a wide range of applications because of their thermal and optical properties. Particle size and size distribution show significant effects in different wavelength ranges, which is very important in specific applications including solar thermal systems in addition to other applications. Radiative properties (scattering and absorption) carry the significant impact on the thermal radiative transfer, where the energy of the incident radiation is converted directly to thermal radiation. Different nanoparticles in different conditions show different radiative properties, which can be exploited in the thermal field for specific applications. 
The aim of the using participating media is not only to convert concentrated radiation energy into thermal energy as efficiently as possible but also, to achieve the highest possible temperatures while retaining this high thermal efficiency.

In this study, it can observe that the nanoparticles play a significant role in the UV-Vis wavelength ranges where a large amount of the solar energy is dissipated. The extinction coefficient of the media is enhanced and affects the radiation transfer performance. Particle size and number have important effects on the thermal radiation transfer, increasing particle concentration leads to enhance the radiative properties.

\section{NOMENCLATURE}

A Surface area of the panel $\left(\mathrm{m}^{2}\right)$

AUST Average unheated surface temperature $\left({ }^{\circ} \mathrm{C}\right)$

CFD Computational fluid dynamics

$\mathrm{c}_{\mathrm{p}} \quad$ Specific heat $(\mathrm{J} / \mathrm{kgK})$

$\varepsilon \quad$ Surface emissivity

$\mathrm{E}_{\mathrm{bi}} \quad$ Blackbody emissive power of examined surface $\left(\mathrm{W} / \mathrm{m}^{2}\right)$

$\mathrm{F}_{\mathrm{i}-\mathrm{j}} \quad$ View factor between the examined and $\mathrm{j}$ surfaces

$\mathrm{F}_{\mathrm{s}-\mathrm{j}} \quad$ View factor between the radiant surface and $\mathrm{j}$ surfaces

$\mathrm{F}_{1-\mathrm{n}} \quad$ View factor between the examined surface and the surroundings

$h_{c} \quad$ Convective heat transfer coefficient $\left(W / m^{2} \mathrm{~K}\right)$

$\mathrm{h}_{\mathrm{r}} \quad$ Radiative heat transfer coefficient $\left(\mathrm{W} / \mathrm{m}^{2} \mathrm{~K}\right)$

$\mathrm{h}_{\mathrm{t}} \quad$ Total heat transfer coefficient $\left(\mathrm{W} / \mathrm{m}^{2} \mathrm{~K}\right)$

$\mathrm{J}_{\mathrm{i}} \quad$ Thermal radiosity of examined surface $\left(\mathrm{W} / \mathrm{m}^{2}\right)$

$\mathrm{J}_{\mathrm{j}} \quad$ Thermal radiosity of $\mathrm{j}$ surface $\left(\mathrm{W} / \mathrm{m}^{2}\right)$

$\mathrm{Q}_{\mathrm{c}} \quad$ Convective heat transfer (W)

$\mathrm{Q}_{\mathrm{r}} \quad$ Radiative heat transfer $(\mathrm{W})$

$\mathrm{q}_{\mathrm{c}} \quad$ Convective heat flux $\left(\mathrm{W} / \mathrm{m}^{2}\right)$

$\mathrm{q}_{\mathrm{r}} \quad$ Radiative heat flux $\left(\mathrm{W} / \mathrm{m}^{2}\right)$

$\mathrm{q}_{\mathrm{t}} \quad$ Total heat flux $\left(\mathrm{W} / \mathrm{m}^{2}\right)$

$\mathrm{R} \quad$ Correlation coefficient

$T_{a}, T_{o p}, T_{c}, T_{s}, T_{w}$ Air temperature, operative temperature, ceiling temperature, floor temperature, and temperature of walls $\left({ }^{\circ} \mathrm{C}\right)$

$\Delta \mathrm{T} \quad$ Temperature difference between radiant heated wall and reference temperature at corresponding heat transfer coefficients

\section{REFERENCES}

[1] Wu, X., Zhao, J., Olesen, B. W., Fang, L., \& Wang, F. (2015). A new simplified model to calculate surface temperature and heat transfer of radiant floor heating and cooling systems. Energy and Buildings, 105, 285-293.

[2] Zhao, M., Gu, Z. L., Kang, W. B., Liu, X., Zhang, L. Y., Jin, L. W., \& Zhang, Q. L. (2017). Experimental investigation and feasibility analysis on a capillary radiant heating system based on solar and air source heat pump dual heat source. Applied energy, 185, 2094-2105.

[3] Evren, M. F., Özsunar, A., \& K1lkış, B. (2016). Experimental investigation of energy-optimum radiant-convective heat transfer split for hybrid heating systems. Energy and Buildings, 127, 66-74.

[4] Zhao, K., Liu, X. H., \& Jiang, Y. (2014). On-site measured performance of a radiant floor cooling/heating system in Xi'an Xianyang International Airport. Solar Energy, 108, 274-286.

[5] Zhang, D., Xia, X., \& Cai, N. (2016). A dynamic simplified model of radiant ceiling cooling integrated with underfloor ventilation system. Applied Thermal Engineering, 106, 415-422.

[6] Bojić, M., Cvetković, D., \& Bojić, L. (2015). Decreasing energy use and influence to environment by radiant panel heating using different energy sources. Applied energy, 138, 404-413.

[7] Feng, J. D., Schiavon, S., \& Bauman, F. (2016). New method for the design of radiant floor cooling systems with solar radiation. Energy and buildings, 125, 9-18. 
[8] Bojić, M., Cvetković, D., Marjanović, V., Blagojević, M., \& Djordjević, Z. (2013). Performances of low temperature radiant heating systems. Energy and Buildings, 61, 233-238.

[9] Shin, M. S., Rhee, K. N., Ryu, S. R., Yeo, M. S., \& Kim, K. W. (2015). Design of radiant floor heating panel in view of floor surface temperatures. Building and Environment, 92, 559-577.

[10] Awbi, H. B. (1998). Calculation of convective heat transfer coefficients of room surfaces for natural convection. Energy and buildings, 28(2), 219-227.

[11] Giovannelli, A., \& Bashir, M. (2017). Charge and discharge analyses of a PCM storage system integrated in a high-temperature solar receiver. Energies, 10(12), 1943.

[12] Causone, F., Corgnati, S. P., Filippi, M., \& Olesen, B. W. (2009). Experimental evaluation of heat transfer coefficients between radiant ceiling and room. Energy and Buildings, 41(6), 622-628.

[13] Koca, A., Acikgoz, O., Çebi, A., Çetin, G., Dalkilic, A. S., \& Wongwises, S. (2017). An experimental investigation devoted to determine heat transfer characteristics in a radiant ceiling heating system. Heat and Mass Transfer/WaermeUnd Stoffuebertragung, pp. 1-13.

[14] Cholewa, T., Rosiński, M., Spik, Z., Dudzińska, M. R., \& Siuta-Olcha, A. (2013). On the heat transfer coefficients between heated/cooled radiant floor and room. Energy and Buildings, 66, 599-606.

[15] Andrés-Chicote, M., Tejero-González, A., Velasco-Gómez, E., \& Rey-Martínez, F. J. (2012). Experimental study on the cooling capacity of a radiant cooled ceiling system. Energy and Buildings, 54, 207-214.

[16] EN 1264-5, Water Based Surface Embedded Heating and Cooling Systems - Part 5 (2008): Heating and Cooling Surfaces Embedded in Floors, Ceilings and Walls.

[17] EN 15377-1, Heating Systems in Buildings - Design of Embedded Water Based Surface Heating and Cooling Systems - Part 1 (2008): Determination of the Design Heating and Cooling Capacity.

[18] Koca, A., \& Çetin, G. (2017). Experimental investigation on the heat transfer coefficients of radiant heating systems: Wall, ceiling and wall-ceiling integration. Energy and Buildings, 148, 311-326.

[19] Awbi, H. B. (1998). Calculation of convective heat transfer coefficients of room surfaces for natural convection. Energy and Buildings, 28(2), 219-227.

[20] Acikgoz, O., \& Kincay, O. (2015). Experimental and numerical investigation of the correlation between radiative and convective heat-transfer coefficients at the cooled wall of a real-sized room. Energy and Buildings, 108, $257-266$. [21] Acikgoz, O. (2015). A novel evaluation regarding the influence of surface emissivity on radiative and total heat transfer coefficients in radiant heating systems by means of theoretical and numerical methods. Energy and Buildings, $102,105-116$.

[22] Karadağ, R. (2009). New approach relevant to total heat transfer coefficient including the effect of radiation and convection at the ceiling in a cooled ceiling room. Applied Thermal Engineering, 29(8-9), 1561-1565.

[23] Demir, H., Dalkilic, A. S., Kürekci, N. A., Duangthongsuk, W., \& Wongwises, S. (2011). Numerical investigation on the single phase forced convection heat transfer characteristics of $\mathrm{TiO} 2$ nanofluids in a double-tube counter flow heat exchanger. International Communications in Heat and Mass Transfer, 38(2), 218-228.

[24] Seyam, S., Huzayyin, A., El-Batsh, H., \& Nada, S. (2014). Experimental and numerical investigation of the radiant panel heating system using scale room model. Energy and Buildings, 82, 130-141.

[25] Incropera, F. P., DeWitt, D. P., Bergman, T. L., \& Lavine, A. S. (2007). Heat and Mass Transfer - Incropera 6e. Fundamentals of Heat and Mass Transfer.

[26] Rahimi, M., \& Sabernaeemi, A. (2010). Experimental study of radiation and free convection in an enclosure with a radiant ceiling heating system. Energy and Buildings, 42(11), 2077-2082. 